\title{
Proposal And Effectiveness Of A Highly Compelling Direct Mail Method - Establishment And Deployment Of PMOS-DM
}

Hisatoshi Ishiguro, Aoyama Gakuin University, Japan Kakuro Amasaka, Aoyama Gakuin University, Japan

\begin{abstract}
No clear processes are used at car dealers when deciding target customers for direct mail campaigns, and individual sales representatives rely on their experience when making such decisions. This means that dealer strategies lose their effectiveness and dealers fail to achieve the desired increase in customer visits. Thus, for this study, the author has established the Practical Method using Optimization and Statistics for Direct Mail (PMOS-DM) as a method of deciding the most suitable target customers for direct mail campaigns. Specifically, in order to both clarify the dealer's target customer types and increase the number of customer visits, the author applied mathematical programming (combinatorial optimization) using statistical science to establish a model for determining the most suitable target customers for direct mail campaigns. This model has subsequently been applied at company $M$ dealers, demonstrating significant effectiveness in increasing customer visits.
\end{abstract}

Keywords: Marketing; Direct Mail; Numeric Simulation; PMOS-DM

\section{INTRODUCTION}

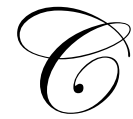

hanges in the recent marketing environment have made the personal relationship between businesses and their customers even more critical. Businesses are faced with the task of constructing sales schemes that are able to flexibly and accurately grasp peculiarities and trends in customer preferences. This study looks at the effectiveness of the direct mail advertising method in bringing customers to auto dealers, based on the idea that forming personal bonds with customers is a core component of successful sales. One of the unique features of direct mail is the advertiser's ability to select which customers will receive the mailings. This point is the focus of this study, which attempts to identify an optimum decision-making process for selecting target customers.

The way that dealers currently select which customers will receive direct mail is by having individual salespeople choose them on the basis of personal experience and knowledge. Because there is no clear decisionmaking process, the response rate is lower than expected and dealers do not achieve the targets set forth in their sales strategies.

To address these issues, this study presents a methodology for selecting direct mail recipients from the dealer pool that will result in increased response (dealer visit) rates. The proposed mechanism for selecting these optimum recipients is the PMOS-DM model. This model uses mathematical programming and statistics to aid the decision-making process and boost the effectiveness of direct mail advertising. 


\section{IMPORTANCE OF STRATEGIC ADVERTISING}

Though Japanese companies are estimated to have spent a total of around six billion yen in advertising over the past four years, the results have not been significant. Businesses need marketing activities that can maximize the effects of their limited advertising budgets. The fact that the auto industry tops the list in terms of money spent on advertising highlights the critical role that promotional efforts play at these companies.

Activities that involve sales divisions searching in isolation for short-term strategies no longer work in today's market. The 4P strategy (Product, Price, Place - distribution channel- and Promotion) is a typical example. Instead, companies must work with divisions both inside and outside their organizations to develop a strategic approach to marketing activities that gives them central and far-reaching role in their business operations.

The key to today's marketing activities is making full use of customer data in a way that goes beyond traditional customer surveys. In an age when our lives are saturated with physical objects, consumer studies may be the the only way to identify customers' internal wants and needs.

Modern advances in information technology and the ability to utilize POS data and other electronic transactions data enables businesses to conduct up-to-date analyses of vast amounts of customer purchase histories using data mining tools and other techniques. It is now possible to analyze the changing and evolving behavior of customers and gain an even greater understanding of their preferences.

Accordingly, marketing tools are also undergoing significant and far-reaching changes. Market segmentation based on simple, observable customer characteristics like age, gender, business size, and business category being replaced with "latent clustering" or "latent class analysis segmentation methods" that look at the underlying desires and preferences of customers.

\section{DIRECT MAIL}

Because this study targets direct mail advertising, the following provides some background information on the role of direct mail in advertising and how this method is currently being put into practice.

\section{Role in Advertising}

When looking at advertising effectiveness, there are many models available that track the stages of psychological change in customers as they move from the point the first encounter an advertisement to the point where they actually purchase the product. Today's advertising information processing models are largely based the AIDA model, first proposed by Elias St. Elmo Louis in 1898. The AIDA model breaks down the psychology of customer purchasing behavior into four steps from which the acronym is derived: Attention, Interest, Desire, and Action.

Television commercials and other advertising and promotion activities seek to target customer attention, which is the first stage in the AIDA theory. Newspaper inserts attempt to move customers into the psychological stages of interest and desire. In other words, advertising media that dealers use to increase the number of customers visiting the shop (such as newspaper inserts or direct mail), are extremely important. Furthermore, dealers that are firmly established in the community play a critical role in forming personal relationships with customers.

Direct mail in particular is a means of pinpointing specific consumers that the dealer wishes to provide with information. Because it works in a direct manner, it is considered an important advertising method for increasing the number of customers who come into the shop. In other words, direct mail is an effective means of developing personal relationships between the dealer and its customers. 


\section{Current Process}

This section describes the way that direct mail activities are actually carried out. First, dealer headquarters puts together an event and creates the associated direct mail materials. The individual dealer shops then determine how many of the mailings to send out. Then, dealer salespeople then use this number to decide who among their customers will receive the mailings. At this point, each member of the sales staff makes an individual decision about who to target. The selection process is vague and inexplicit.

Take for example the process when a vehicle model is completely redesigned and the new cars first go on sale. Dealers decide to send out direct mailings announcing the new vehicle, hoping to target customers who will be receptive to the design concept. However, the salespeople often fail to consider this strategy, with veteran staff members sending information only to their best customers and new staff members sending it to whomever they happen to have access to.

Several problems arise from this process. First, the direct mailings result in an extremely low response rate. Second, dealer salespeople are not choosing the same customers that the dealer wishes to target. And third, because the process is not well defined, the quality of work performed by different sales personnel is highly inconsistent. Because of these factors, dealers are currently failing to make their direct mail activities effective.

\section{Related Works}

A search of previous research on direct mail both in Japan and overseas found no enough examples of studies that focused on strategies for selecting target customers. Instead, direct mail research tended to focus on optimizing mailing frequency, the reasons customers chose to visit dealers upon receiving direct mail, which customers were most likely to visit the dealer after receiving direct mail, and the design features of the actual direct mail materials.

\section{THE PMOS-DM MODEL}

Because dealers are currently not making effective use of direct mail, this paper presents the PMOS-DM model to boost the ability of direct mail activities to bring in customers.

\section{Research Aims}

The new model uses a three-pronged approach to resolving dealers' current problems with direct mail activities. The first goal is to increase the response rate, or the percentage of customers who visit the dealer as a result of receiving direct mail. To achieve this, the PMOS-DM model uses statistical analysis to determine which customers are most likely to respond. The second is to reflect dealer aims in the recipient selection process. This is achieved by using a simulation driven by mathematical programming to optimize the selection of target customers. Finally, the third goal is to clarify the recipient selection process by providing dealers with a model that outlines a specific approach. Following an explicit model informed by statistics and mathematical programming keeps inconsistency among salespeople to a minimum. The three-pronged approach proposed in this study therefore provides a direct mail method that allows dealers to both target their desired customer segment and boost response rates at the same time.

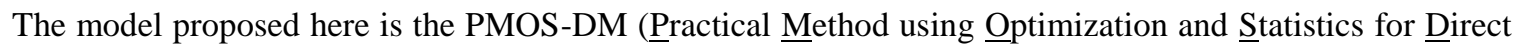
Mail). In short, it uses statistics and mathematically programming for an objective decision-making process that does not rely on the current selection methods used by salespeople, which are based on personal knowledge and experience and therefore vague and inexplicit. At the same time, the model aims to boost the direct mail response rate in line with dealer targets. 


\section{The PMOS-DM Method}

Figure 1 shows the PMOS-DM direct mail method, which is designed to effectively bring customers into the dealer. The model works according to the following method. Step 1 of the process organizes customer information for analysis. Step 2 identifies the customer segments that are most likely to be influenced to visit the dealer as a result of direct mail. Step 3 then runs a numerical simulation to select direct mail recipients. Finally, Step 4 evaluates the mix of target customers identified in Step 3.

\section{OPTIMAL SELECTION USING A MODEL FORMULA}

In its numerical simulation, the PMOS-DM model uses a mathematical formula to select target customers for direct mail. In coming up with a formula to determine who should be targeted by direct mail, the authors referred to the formulas shown in (1) and (2) below, which were developed by Kojima et al.

$\operatorname{MIN} \sum_{m \in M} W^{m}\left(\sum_{j \in J} f_{j}^{m} x_{j}-C R^{m}\right)^{2}$

subject to $\quad L^{m} C \leq \sum_{j} f_{j}^{m} x_{j} \leq H^{m} C$

$m \quad$ Customer attributes (e.g. sex, age, age of current vehicle)

j Customer number

$W^{m} \quad$ Weighting for customers with customer attributes $m$ in direct mail target group

$f_{j}^{m} \quad$ Indicates whether or not customer $j$ has attribute $m(0$ or 1$)$

$x_{j} \quad$ Marks customer $j$ for direct mailing ( 0 or 1 )

$R^{m} \quad$ Ideal percentage with customer attributes $m$ in direct mail target group

$C \quad$ Total number of direct mailing sent

$L^{m} \quad$ Lower limit for the percentage of direct mailings sent to customers with attribute $m$

$H^{m} \quad$ Upper limit for the percentage of direct mailings sent to customers with attribute $m$

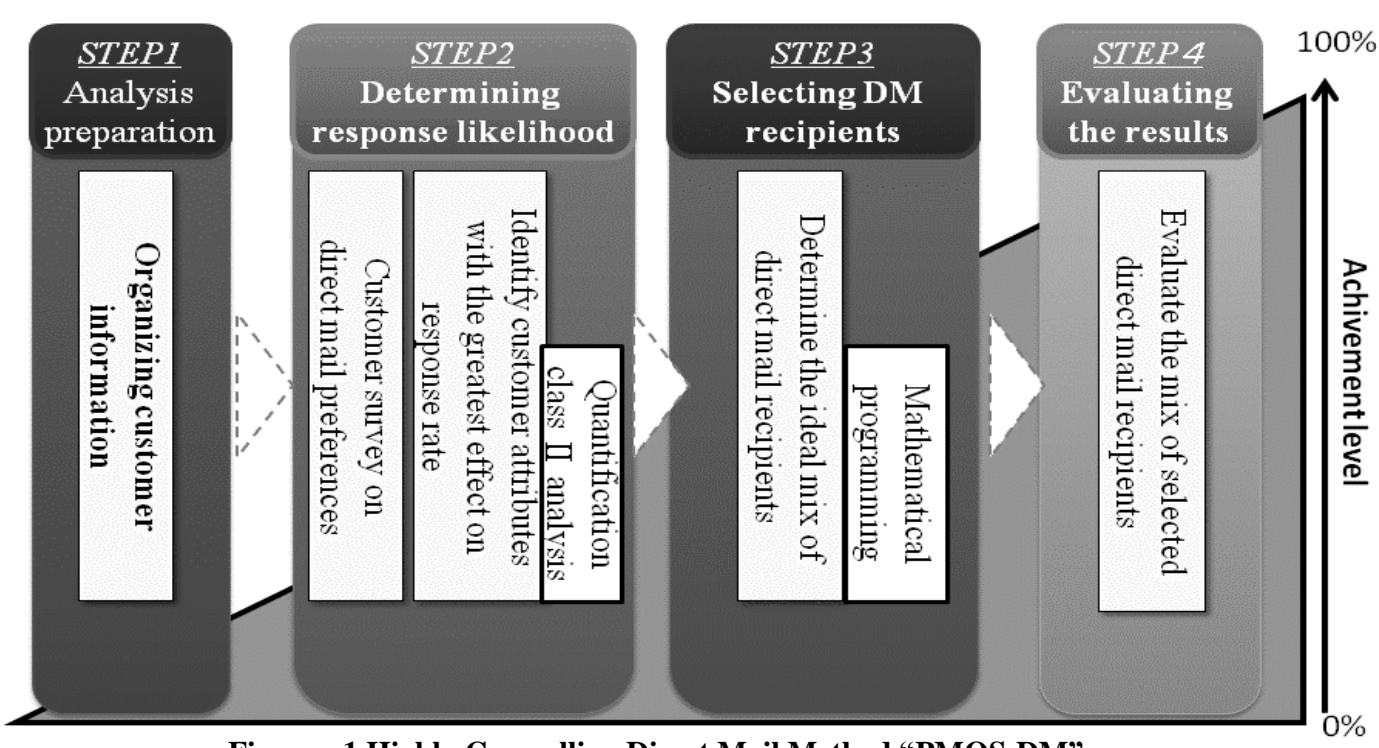

Figure: 1 Highly Compelling Direct Mail Method "PMOS-DM" 
The target function of formula (1) is to minimize the gap between the ideal number of direct mailings sent to customers with attribute $\mathrm{m}\left(\mathrm{CR}^{\mathrm{m}}\right)$ and the number actually sent to customers with that attribute $\left(\Sigma \mathrm{f}_{\mathrm{j}}^{\mathrm{m}} \mathrm{x}_{\mathrm{j}}\right)$. In other words, the formula expresses the concept of setting a target value when sending out direct mail. Accordingly, the formula can be adapted to cases where a clear, rational target value can be set.

However, the formula cannot be used when it is difficult to set a logical target value for the number of direct mailings to be sent - and a dozen or so of the dealers that the authors studied did not set one. For those dealers, the authors set up a formula that would clarify the process that senior sales staff used to determine who should be targeted by a given direct mail campaign.

In the process of conducting interviews, the authors learned that senior sales staff uses an abstract method of targeting those customers who seem like they would have an easy time coming into the dealer. The authors then constructed a makeshift definition of this group of customers as follows.

Each group of customers defined by a given attribute (male, female, 20s, 30s, etc.) has different preferences that would motivate them to come into the dealer. Each customer's willingness to come in can be assigned a cumulative value based on that person's attributes. Those with a high cumulative value can be considered the ones who are likely to come into the shop.

With this line of thinking, the authors developed a formula for calculating the total willingness for customers targeted by direct mail. They then constructed a model for optimizing those values. Finally, the authors came up with a set of constraints in order to put limits on the number of mailings dealers would send, with the aim of maximizing the effectiveness of those that were sent.

\section{Model Formula}

This is the model formula used in the numerical simulation.

$$
\begin{aligned}
& \operatorname{MAX} \sum_{m}\left(E^{m} \sum_{j}\left(f_{j}^{m} x_{j}\right)\right) \\
& \text { subject to } \sum_{j} x_{j}=C \\
& L^{m} C \leq \sum_{j} f_{j}^{m} x_{j} \leq H^{m} C
\end{aligned}
$$

$m \quad$ Customer attributes (e.g. sex, age, age of current vehicle)

$j \quad$ Customer number

$E^{m} \quad$ Effect of customer attribute $(m)$ on the likelihood that the customer will visit the dealer

$f_{j}^{m} \quad$ Indicates whether or not customer $j$ has attribute $m(0$ or 1$)$

$x_{j} \quad$ Marks customer $j$ for direct mailing $(0$ or 1$)$

C Total number of direct mailing sent

$L^{m} \quad$ Lower limit for the percentage of direct mailings sent to customers with attribute $m$

$H^{m} \quad$ Upper limit for the percentage of direct mailings sent to customers with attribute $m$

This mathematical formula is designed to determine a value for the variable $x_{j}$. If the value is 1 , mailings should be sent to the customer number indicated by $j$. If it is 0 , a direct mailing should not be sent. The other variables are parameters that must be given values before solving the formula. $C, L^{m}$, and $H^{m}$ are set at the discretion of whoever is sending out the direct mail. The value $f_{j}^{m}$ is determined based on the customer information that the dealer has. $E^{m}$ is determined later via statistical analysis. 
The roles of the individual formulas are as follows. The objective function in formula (3) is used to maximize the customer response rate (the percentage of customers that come to the dealer as a result of the direct mail). The constraint in formula (4) determines the number of direct mailings that are to be sent out. The constraint in formula (5) determines how many direct mailings are to be sent to each customer segment, which is how dealer aims are incorporated into the model.

The mathematical formula is designed so that the number of customer attributes it handles $(m)$ can be increased at will. Depending on what customer information dealers have, they can limit these attributes to basic life stages or expand them to include hobbies, preferences, and other lifestyle characteristics.

\section{Recipient Selection Process}

This section describes the procedure for using the mathematical formula provided to select direct mail recipients. First, a "response likelihood" value must be set for each customer using the variable $E^{m}$. The list of customers is then reordered with those with the highest likelihood of responding at the top. The purpose of the objective function in formula (3) is to order customers according to their likelihood of responding (visiting the dealer as a result of direct mail). Next, this list is used to select the number of customers equal to the number of direct mailings (the constraint) to be sent out, starting with those most likely to respond. For example, if 50 direct mailings are to be sent, they would be sent to the top 50 customers most likely to respond to them. This is the basic principle behind the development of the formulas.

In addition, when the dealer has a specific aim in mind (e.g. sending a large number of direct mailings to women), the constraint function in formula (5) can be used to incorporate that aim in the calculations. For example, if the dealer wanted at least $60 \%$ of the 50 mailings to go to women, the women customers would be listed in order of response likelihood and the top 30 customers would be selected to receive direct mail. The remaining 20 recipients would be selected from the entire pool of target customers in order of their response likelihood as well. The purpose of this function is to allow dealers to use their marketing strategies to boost response rate.

\section{PUTTING PMOS-DM TO WORK}

The researchers teamed up with Company $\mathrm{M}$ to use the PMOS-DM to guide direct mailing efforts in conjunction with an event showcasing multiple new vehicle models. The following sections show how the model was applied.

\section{Organizing Customer Information (Step \#1)}

Since this study requires customer information to select direct mail recipients, raw customer data used by Company M dealers was collected. Participating dealers had information on a total of 391 customers, which included data on sex (male/female), age (20s, 30s, 40s, 50s, 60+), and age of current vehicle (3-5 years, 6-8 years, $9+$ years). Therefore, there were a total of 391 values assigned to $j$ in the formula, and a total of 10 different values assigned to $m$.

A binary code ( 0 or 1$)$ was then assigned to the collected customer information in order to analyze it. This resulted in values for the $f_{j}^{m}$ variable. Recipients of direct mailing could now be determined based on the dealers' customer information.

\section{Determining Response Likelihood (Step \#2)}

The next step was to conduct a survey and analyze the data to determine which customer attributes were most likely to lead customers to visit a dealer as a result of receiving direct mail. The survey method used in this study was to ask customers of varying attributes (sex, age, vehicle age, etc.) whether receiving direct mail had ever caused them to visit the dealer. Once the results were collected, they were quantified and subjected to a Type II analysis determine which customers had the highest likelihood of responding to direct mail. This made it possible to analyze customer attributes in terms of whether or not they were likely to lead to a dealer visit in terms of an external standard. These response likelihood values were then assigned the variable $E^{m}$. 
The formula below shows the results of this analysis. The discriminant ratio for the analysis results was $77.36 \%$, indicating that they were fairly reliable.

The linear discriminant formula produced from the analysis results is below.

$$
\begin{aligned}
& y=0 x_{11}-1.4 x_{12} \\
& +0 x_{21}+0.9 x_{22}+2.1 x_{23}+3.7 x_{24}+1.7 x_{25} \\
& +0 x_{31}-1.3 x_{32}-0.9 x_{33}-1.4
\end{aligned}
$$

If the linear discriminant is greater than 0 , the customer is likely to visit the dealer as a result of receiving direct mail. If it is less than zero, it indicates that they are not likely to visit. Therefore, the coefficient produced by this formula indicates the response likelihood for the customer attribute as expressed by $E^{m}$. The results of this analysis, which allowed us to identify which customers were likely to visit the dealer, are summarized in Table 1.

Table 1: Response Likelihood by Attribute

\begin{tabular}{|l|c|}
\hline \multicolumn{1}{|c|}{ Customer attribute } & Response likelihood \\
\hline Men & 0 \\
\hline Women & -1.4 \\
\hline 22-29 years old & 0 \\
\hline 30-39 years old & 0.89 \\
\hline 40-49 years old & 2.1 \\
\hline 50-59 years old & 3.7 \\
\hline 60+ years old & 1.7 \\
\hline Currently driving a vehicle 3-5 years old & 0 \\
\hline Currently driving a vehicle 6-8 years old & -1.3 \\
\hline Currently driving a vehicle 9+ years old & -0.9 \\
\hline
\end{tabular}

\section{Selecting DM Recipients (Step \#3)}

In the next step, direct mail recipients are selected based on a numerical simulation. This section describes the simulation procedure. First, the customer information collected in Step 1 is plugged into $f_{j}^{m}$, and the information on response likelihood for each customer attribute is plugged into $E^{m}$. The number of direct mailings to be sent is plugged into $\mathrm{C}$. The upper and lower limits for the percentage of direct mailings to go to customers with each attribute is set at the dealer's discretion using the variables $H^{m}$ and $L^{m}$. Once all the parameters are set, the simulation is carried out. The formula given in chapter 5 is solved, and the optimum customers to receive direct mailings are selected.

During this process, formulas (3) through (5) are solved as a weighted constraint satisfaction problem. In the weighted constraint satisfaction problem, the weighted constraints are moved to the target function as in (7), where they are added as a way of minimizing the level of deviation outside of the given limits. Even if a feasible solution that satisfies the constraints does not exist, the formula allows dealers to come as close as possible to meeting the constraints. Here, in constraining the number of mailings sent to customers with the attributes defined in formula (5), it is difficult to set customer attributes $L^{m}$ and $H^{m}$, ensuring that a feasible solution is more likely to exist. Therefore, when approaching the issue as weighted constraint satisfaction problem, it is best to find a solution that best satisfies formula (5). In other words, this allows dealers to send direct mail to those customers most likely to come into the shop based on dealer strategy. 


$$
\begin{aligned}
\text { MIN } & -\sum_{m}\left(E^{m} \sum_{j}\left(f_{j}^{m} x_{j}\right)\right) \\
& +\sum_{m} W^{m}\left(L^{m} C-f_{j}^{m} x_{j}\right) \\
& +\sum_{m} W^{m}\left(H^{m} C-f_{j}^{m} x_{j}\right)
\end{aligned}
$$

\section{Evaluating the Results (Step \#4)}

Once the recipients of direct mailings are selected based on the simulation, whoever is sending out the direct mail checks the simulation results to make sure that they accurately reflect the dealer's marketing strategy. If the desired results are not achieved, the causes for the discrepancy are identified, the parameters are adjusted, and the simulation is run again.

\section{EFFECTIVENESS OF PMOS-DM}

The effectiveness of the PMOS-DM model was assessed by comparing the response rates (percentage of direct mail recipients who visited the dealer as a result) when salespeople selected direct mail recipients based on personal knowledge and experience and when recipients were selected using the model. Five new models were showcased at the event held by Company M. Four of the design concepts targeted female buyers, and one targeted male buyers. As a result, the dealer's marketing strategy was to target women in particular throughout a wide range of age groups. This strategy was thus taken into account when verifying the effectiveness of the model.

These verification results are summarized in Table 2. The response rate when direct mail recipients were selected on the basis of personal knowledge and experience of the sales staff was $19 \%$. When selection was made using the PMOS-DM model, the rate was $20.4 \%$.

Table 2: Verification Results (All)

\begin{tabular}{|l|c|c|}
\hline & Dealer & PMOS-DM \\
\hline Number of direct mailings sent & 269 & 59 \\
\hline Number of resulting dealer visitors & 51 & $20.4 \%$ \\
\hline Response rate & $19.0 \%$ & 59 \\
\hline
\end{tabular}

Table 3 shows the same information for female customers only (those targeted in the dealer's marketing strategy). Salespeople generated a $4.2 \%$ response rate using their personal knowledge and experience, while the model generated a $19.8 \%$ response rate, signaling a significant improvement. The effectiveness of the model was thereby verified in the course of this study.

Table 3: Verification Results (Women)

\begin{tabular}{|l|c|c|}
\hline & Dealer & PMOS-DM \\
\hline Number of direct mailings sent & 48 & 61 \\
\hline Number of resulting dealer visitors & 2 & 12 \\
\hline Response rate & $4.2 \%$ & $19.8 \%$ \\
\hline
\end{tabular}




\section{CONCLUSION}

The present study sought to resolve problems with the effectiveness of direct mailing activities at dealers. Its purpose was to improve the direct mail response rate by accurately reflecting dealer marketing strategy in the recipient selection process. The PMOS-DM model was developed in order to select optimum direct mailing recipients and thus achieve these aims. Its effectiveness was then verified through application at actual dealers where an increase in response rate was demonstrated.

It is hoped that customer attributes will be studied in more detail in the future and will no longer be limited to the three presented here (i.e., sex, age, and age of current vehicle). This added customer information will result in a more precise simulation outcome.

\section{AUTHOR INFORMATION}

Hisatoshi Ishiguro is a graduate student of the College of Science and Engineering at Aoyama Gakuin University. E-mail: c5610162@aoyama.jp

Dr. Kakuro Amasaka is a Professor in the College of Science and Engineering at Aoyama Gakuin University, Japan. He received his Ph.D. degree in Precision Mechanical and System Engineering, Statistics and Quality Control at Hiroshima University in 1997. Since joining Toyota Motor Corporation in 1968, He worked as a quality control consultant for many divisions, and the General Manager of the TQM Promotion Division (1998-2000). His specialty is New JIT, Science TQM, Science SQC, Numerical Simulation (CAE) and Customer Science. Now, He has been serving as the vice chairman of JSPM (2003-2007) and JOMSA (2008-), the director of JSQC (2001-2003). E-mail: Kakuro_amasaka@ise.aoyama.ac.jp. Corresponding author

\section{REFERENCES}

1. Dentsu, Japanese total advertisement rates, http://www.dentsu.co.jp/. (in Japanese)

2. Toyo Keizai Inc., Advertisement rates top 100, http://www.toyokeizai.net/. (in Japanese)

3. K. Amasaka, "The validity of advanced TMS, A strategic development marketing system-Toyota's scientific customer creative model utilizing New JIT-“, The International Business \& Economics Research Journal, Vol. 6, No. 8, 2007, pp35-42.

4. $\quad$ K. Amasaka, Science SQC. New quality control principle, Springer, 2004

5. K. Shimizu, Theory and strategy of advertisement, Souse publishers, 2004. (in Japanese)

6. M. Shibasaki, Y. Morimune, "Attribution analysis in effect of TV commercial to use AIDA theory", Amasaka-laboratory Study Group, 2000. (in Japanese)

7. T. Shiode, M. Kawamura, "Attribution analysis in effect of TV commercial to use AIDA theory (part2)", Amasaka-laboratory Study Group, 2001. (in Japanese)

8. Y. Jinno, M. Tabei, "Attribution analysis on flyer advertisement for increasing the effects of drawing customers", Amasaka-laboratory Study Group, 2001. (in Japanese)

9. J. J. Jonker, N. Piersma, R. Potharst, “A decision support system for direct mailing decision”, Decision Support Systems, Vol. 42, 2006, pp915-925.

10. Y. Asahi, K. Jitama, Y. Sugihara, T, Namatame, T. Yamaguchi, "Identifying latent factors driving department store purchases: A direct mail strategy", Operations research as a management science research, Vol. 49, No. 2, 2004, pp75-80. (in Japanese)

11. J. R. Bult, T. Wansbeek, “Optimal selection for direct mail”, Marketing Science, Vol. 14, No. 4, 2005 pp378-394.

12. T. Kimura, M. Yamaji, K. Amasaka, "A study of "Scientific Approach Method for Direct Mail, SAM-DM" effectiveness of attracting customer utilizing Advanced TMS", Proceedings of the $5^{\text {th }}$ Asian Quality Congress, Incheon, Korea, 2007, pp938-945.

13. T. Kojima, T. Kimura, M. Yamaji, K. Amasaka, "Proposal and development of the direct mail method "PMOS-DM" for effectively attracting customers", International Journal of Management and Information Systems, Vol. 14, No. 5, 2010, pp15-22 
\begin{tabular}{ll} 
International Journal of Management \& Information Systems - First Quarter $2012 \quad$ Volume 16, Number 1 \\
\hline
\end{tabular} NOTES 